\title{
Linear low-density polyethylene/silica micro- and nanocomposites: dynamic rheological measurements and modelling
}

\author{
A. Dorigato*, A. Pegoretti, A. Penati \\ Department of Materials Engineering and Industrial Technologies, University of Trento, 38123 Trento, Italy
}

Received 13 October 2009; accepted in revised form 12 December 2009

\begin{abstract}
Linear low-density polyethylene (LLDPE) based composites were prepared by melt compounding with 1, 2, 3 and 4 vol\% of various kinds of amorphous silicon dioxide $\left(\mathrm{SiO}_{2}\right)$ micro- and nanoparticles. Dynamic rheological tests in parallel plate configuration were conducted in order to detect the role of the filler morphology on the rheological behaviour of the resulting micro- and nanocomposites. A strong dependence of the rheological parameters from the filler surface area was highlighted, with a remarkable enhancement of the storage shear modulus $\left(G^{\prime}\right)$ and of the viscosity $(\eta)$ in fumed silica nanocomposites and in precipitated silica microcomposites, while glass microbeads only marginally affected the rheological properties of the LLDPE matrix. This result was explained considering the formation of a network structure arising from particle-particle interactions due to hydrogen bonding between silanol groups. A detailed analysis of the solid like behaviour for the filled samples at low frequencies was conducted by fitting viscosity data with a new model, based on a modification of the original De Kee-Turcotte expression performed in order to reach a better modelling of the high-frequency region.
\end{abstract}

Keywords: nanocomposites, polyethylene, silica, modelling, rheology

\section{Introduction}

One of the most important consequences of the incorporation of nanofillers in molten polymers is the significant change in their viscoelastic properties [1]. The reduction of the filler size down to nanometric scale can produce substantial differences in the rheology and dynamic of filled polymer in comparison to micron sized particles [2-7]. In fact, polymer composites reinforced with submicron fillers generally show significant enhancements in the viscoelastic properties compared to microcomposites at similar filler contents, associated to the appearance of a secondary plateau for the dynamic storage modulus $\left(G^{\prime}\right)$ in the low frequency regime [3,6-10]. These effects can be explained considering that the extremely large sur- face area provided by nanoparticles can intensify the effect of particle-particle and/or polymer-particle thermodynamic interactions $[4,5,11-14]$. When filler-filler interactions dominate, it is believed that the rheological response of the material is influenced by the destruction and reconstruction of a filler network and/or agglomerates during mechanical loading $[8,9,15,16]$. On the other hand, when polymer-filler interaction is the driving factor, the viscoelasticity of the melt is controlled by the dynamics of the stick-slip motion of the polymer chains around the filler surface [17-22]. During the past few years, the linear viscoelastic behaviour in the molten state of polymer nanocomposites filled with organically modified clays has been widely investigated [23-31], and the subject 
has been reviewed by Krishnamoorti and Yurekli [26]. Studying the rheological response of polystyrene/clay nanocomposites, Zhao et al. [30] found that the level of dispersion was markedly correlated with the rheological response. Gupta et al. [25] prepared a series of ethylene-vinyl acetate/ clay nanocomposites, finding a marked shear thinning behaviour with respect to the unfilled sample at filler loadings higher than $2.5 \mathrm{wt} \%$. Wu et al. [29] prepared polylactide/clay nanocomposites by melt mixing, revealing the formation of a solid-like behaviour for clay loadings higher than $4 \mathrm{wt} \%$, taken as the percolation threshold for the formation of a physical network. With the term percolation threshold, the authors intended a critical concentration above which the distance between clay nanoplatelets was sufficiently low to allow the formation of a space filling network constituted by physical interactions between clay lamellae in steady state conditions. This physical network could be destroyed by the oscillatory large amplitude shear deformation and could be eventually reorganized under quiescent annealing condition. Similar results can be also found in some papers dealing with the rheological behaviour of polymer/carbon nanotubes (CNT) nanocomposites [32-37]. Ganß et al. [33] found a systematic increase in melt viscosity for polypropylene/multiwalled CNT nanocomposites. Abdel-Goad and Pötschke [32] found that the dynamic moduli and the viscosity of polycarbonate/multiwalled CNT composites increased with increasing the CNT content, with a transition from a liquid like to a solid like behaviour at concentrations of only $0.5 \mathrm{wt} \%$. In this case the transition was related to the formation of a combined network between the nanotubes and the polymer chains. Similar conclusions were reported by Song [37] in a paper on the rheological properties of poly(ethylene oxide)/carbon nanotubes composites. Furthermore, Prashantha et al. $[35,36]$ prepared multi-wall carbon nanotubes (MWNTs) filled polypropylene (PP) nanocomposites, utilizing polypropylene grafted maleic anhydride (PP-g-MA), demonstrating that PP-g-MA promotes the dispersion of MWNTs in PP matrix and the interfacial strength, thus greatly improving the rheological percolation threshold and the mechanical properties of the resulting nanocomposites.
Quite surprisingly, very little information are available on the viscoelastic behaviour of silica filled polymer nanocomposites in the molten state [38]. Fumed silica nanoparticles exist in a wide range of size (specific area ranging from 50 to $400 \mathrm{~m}^{2} / \mathrm{g}$ ) and with a variety of surface treatments from hydrophilic to hydrophobic. Due to their fractal structure and their high specific area, fumed silica is subjected to self-aggregation and can consequently form a network of connected or interacting particles in the molten polymer. Consequently, the most important application of fumed silica is the improvement of the rheological properties of paints [38] and for reinforcing elastomers [39]. Bartholome et al. [40] prepared polystyrene/grafted silica nanocomposites, finding significant enhancements of storage shear modulus in the low frequency regime, especially when unmodified silica was utilized. It was also evidenced that the grafted polymer chains on the silica particles surface created a steric repulsion between the filler particles, preventing the formation of a silica network within the polymer matrix, with a consequent decrease of the rheological properties with respect to the untreated silica filled systems. By a 'freeze-drying' technique, Zhang and Archer [10] prepared poly(ethylene oxide) (PEO) based nanocomposites containing isotropic silica nanospheres, in order to study the effects of polymer-particle and particleparticle interactions on viscoelastic properties of the resulting materials. Even in this case, viscoelastic parameters indicated a transition to a solid-like response at low oscillation frequencies for particle volume fractions as low as $2 \%$, dramatically lower than the theoretical percolation threshold (30\%). In order to explain their observations the authors proposed a mechanism in which nanosized silica particles, surrounded by an immobilized shell of PEO, were bridged by much larger polymer molecules. Cassagnau [38] concluded that the solid-like behaviour displayed by polymer-silica nanocomposites is influenced by the silica surface treatment and by the molecular weight of the matrix, and is mainly promoted by particle-particle interaction in fumed silica nanocomposites, while the particlepolymer interaction is the dominant one in colloidal silica nanocomposites. The critical filler concentration beyond which interparticle interactions begin to play an important role on the rheological proper- 
ties, called percolation threshold $\left(\Phi_{c}\right)$, was computed in some papers. Cassagnau [41] studied the viscoelastic properties of nanosilica-filled ethylene vinyl acetate copolymer (EVA, $60 \mathrm{wt} \%$ of vinyl acetate) in the molten state and diluted EVA/xylene solution, finding a liquid-solid transition at $\Phi_{c}=$ $3.3 \mathrm{vol} \%$, independently from the polymer chain regimes (entangled or Rouse regime). Inoubli et al. [42] observed that $2.5 \mathrm{vol} \%$ of silica in polybutylacrylate nanocomposite was very close to the percolation threshold.

Starting from these considerations, the objective of the present work is to investigate the linear viscoelastic behaviour of silica micro- and nanocomposites in the molten state, in order to find, at least from a qualitative point of view, a correlation between the filler characteristics (size and surface area) and the resulting dynamic rheological properties. In order to pursue this scope, a non-polar polymeric matrix, linear low-density polyethylene (LLDPE) and three types of untreated amorphous silicon dioxide $\left(\mathrm{SiO}_{2}\right)$ micro- and nanofillers (i.e. glass microspheres, precipitated silica microparticles, and fumed silica nanoparticles) were used. Experimental data were then analyzed according to some of the existing models [43-46], and a modification of the original De Kee-Turcotte model [44] was proposed to fit rheological data over the entire frequency range.

\section{Experimental section}

A Flexirene ${ }^{\circledR}$ CL10 linear low-density polyethylene (MFI at $190^{\circ} \mathrm{C}$ and $2.16 \mathrm{~kg}=2.6 \mathrm{~g} / 10^{\prime}, M_{n}=$ $27000 \mathrm{~g} / \mathrm{mol}$, density $\left.=0.918 \mathrm{~g} / \mathrm{cm}^{3}\right)$. This material is produced by Polimeri Europa S.p.A. (Mantova, Italy) using Ziegler-Natta catalysis and butene as a comonomer ( $\mathrm{C}_{4}$-LLDPE).

Various types of amorphous silica micro- and nanoparticles were used as fillers:

i) Cores ${ }^{\circledR}$ silica glass microspheres, having a mean particle size of about $50 \mu \mathrm{m}$ and a surface area lower than $1 \mathrm{~m}^{2} / \mathrm{g}$. On the particles sieved in a $32 \mu \mathrm{m}$ mesh, a mean diameter of $18 \pm 3 \mu \mathrm{m}$ was evaluated through optical microscopy.

ii) Sipernat ${ }^{\circledR} 160$ precipitated silica microparticles, supplied by Degussa (Hanau, Germany). Precipitated silica consists of a three-dimensional network of coagulated primary silica particles. The latter grow to sizes higher than $10 \mathrm{~nm}$ before they coagulate to form the aggregated clusters in the micrometric range of size [47, 48]. Despite their micrometric dimensions (7$8 \mu \mathrm{m})$, these microparticles possess elevated surface area values (around $160 \mathrm{~m}^{2} / \mathrm{g}$ ), because of their high surface porosity.

iii) Aerosil ${ }^{\circledR}$ commercial fumed silica nanoparticles, supplied by Degussa (Hanau, Germany). According to the producer's datasheets, Aerosil 200 has a nominal specific surface area (SSA) of about $200 \mathrm{~m}^{2} / \mathrm{g}$, while for Aerosil 380 a nominal SSA value of about $380 \mathrm{~m}^{2} / \mathrm{g}$ is reported on the material data sheet.

Density was measured through a Micromeritics Accupyc ${ }^{\circledR} 1330$ helium pycnometer, while specific surface area was determined by an ASAP $^{\circledR} 2010$ Accelerated Surface Area and Porosimetry machine, according to the Brunauer-Emett-Teller (BET) procedure [49]. Table 1 summarizes the experimental density and SSA values of the silica micro- and nanoparticles used in this work.

Polyethylene chips and all fillers were used as received. The samples were prepared by melt compounding followed by hot pressing. The filler was melt compounded with LLDPE in a Thermo Haake ${ }^{\circledR}$ internal mixer, at $170^{\circ} \mathrm{C}$ for $15 \mathrm{~min}$ and $90 \mathrm{rpm}$. The materials were then hot pressed in a Carver ${ }^{\circledR}$ laboratory press at $170^{\circ} \mathrm{C}$ for $15 \mathrm{~min}$ at low pressure $(0.2 \mathrm{kPa})$, in order to obtain square sheets about $0.8 \mathrm{~mm}$ thick. The filler content was varied between 1 and 4 vol\%. In all figures and in the discussion session, glass microspheres were simply designated as Glass, precipitated silica microparticles were denoted as S160, while fumed silica nanopowders were designated with the letter A200 or A380 depending on the nominal specific surface area. The unfilled matrix is indicated as LLDPE, while the composites were denoted as LLDPE followed by the name of the filler and the

Table 1. Density and specific surface area values of microand nanosilica fillers utilized in this work

\begin{tabular}{|l|c|c|}
\hline \multicolumn{1}{|c|}{ Type of filler } & $\begin{array}{c}\text { Density } \\
{\left[\mathbf{g} / \mathbf{c m}^{\mathbf{3}}\right]}\end{array}$ & $\begin{array}{c}\text { BET surface } \mathbf{a r e a}^{\mathbf{b}} \\
{\left[\mathbf{m}^{\mathbf{2}} / \mathbf{g}\right]}\end{array}$ \\
\hline Glass microspheres & $2.43 \pm 0.01$ & $0.5 \pm 0.1$ \\
\hline Sipernat 160 & $1.85 \pm 0.01$ & $168.3 \pm 0.6$ \\
\hline Aerosil 200 & $2.27 \pm 0.02$ & $196.6 \pm 1.7$ \\
\hline Aerosil 380 & $2.41 \pm 0.02$ & $320.8 \pm 3.4$ \\
\hline
\end{tabular}

aMeasured through a Micromeritics Accupyc ${ }^{\circledR} 1330$ helium pycnometer

bMeasured through ASAP ${ }^{\circledR} 2010$ Accelerated Surface Area and Porosimetry machine 
filler volume content (vol\%). For example LLDPEA200-2 indicates 2 vol\% Aerosil 200 fumed silica nanocomposite sample.

Observations of the fracture surface of LLDPEGlass-2 composites were taken by using a Philips ${ }^{\circledR}$ XL30 environmental scanning electron microscope (ESEM), at an acceleration voltage between 15 and $30 \mathrm{kV}$. Thin samples $(0.6 \mathrm{~mm})$ were cryofractured under impact conditions and prepared for the observations. Transmission electronic microscope (TEM) images of LLDPE-A380-2 and LLDPE-S160-2 samples were taken by a Philips ${ }^{\circledR} /$ FEI CM120 microscope, at an accelerating voltage of $80 \mathrm{kV}$. Thin sections of the samples were ultramicrotomed at a temperature of $-70^{\circ} \mathrm{C}$ by using a ReichertJung ${ }^{\circledR}$ Ultracut FC4E crio-ultramicrotome.

Dynamic rheological tests were conducted by a TA Instruments ${ }^{\circledR}$ Ares Rheometer in parallel plate configuration, at a temperature of $190^{\circ} \mathrm{C}$. Plates with a diameter of $25 \mathrm{~mm}$ and a distance of $0.8 \mathrm{~mm}$ were chosen for these tests. A maximum shear strain $\left(\gamma_{0}\right)$ of $1 \%$ was imposed to the samples, while the frequency range was varied between 0.05 and $200 \mathrm{rad} / \mathrm{s}$.

\section{Results and discussions}

\subsection{Microstructural characterization}

The rheological behaviour of particulate filled polymers strongly depends on the particle size and dispersion degree. In Figure 1a an ESEM image of the fracture surface of LLDPE-Glass-2 composite is reported. The typical microstructure of particulate filled microcomposites is evidenced, with the presence of spherical smooth microparticles with mean dimension of about 15-20 $\mu \mathrm{m}$, homogeneously distributed through the sample. In Figures $1 b$ and $1 c$ TEM images of the fracture surfaces of LLDPE-S160-2 and LLDPE-A380-2 composites are respectively reported. Precipitated silica composite is characterized by the presence of almost equiaxial aggregates of about $400 \mathrm{~nm}$ in diameter, homogeneously dispersed in the matrix. Before melt compounding S160 microparticles had a mean diameter of about $7-8 \mu \mathrm{m}$. Therefore, the shear forces acting on the highly porous precipitated silica microparticles during the compounding process led to their partial disgregation. This hypothesis is confirmed by similar observations on polymers filled by precipitated silica as reported by Shim and

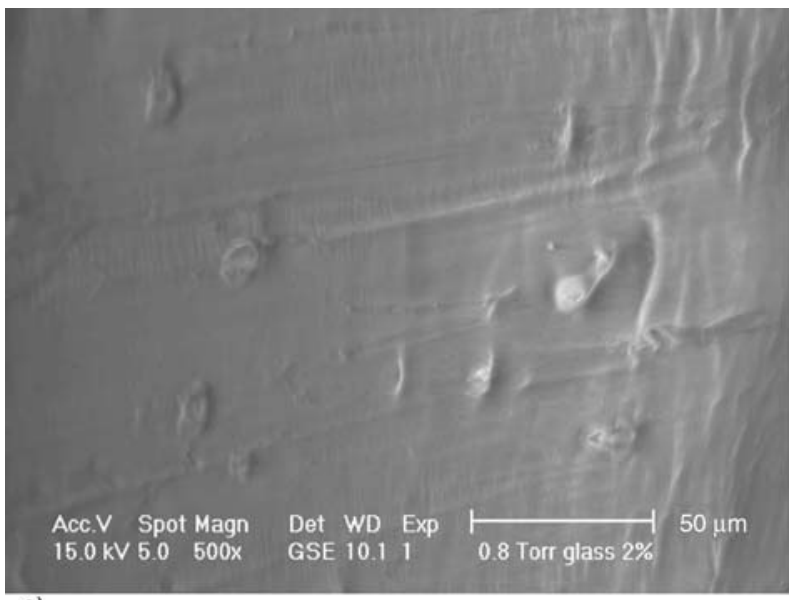

a)
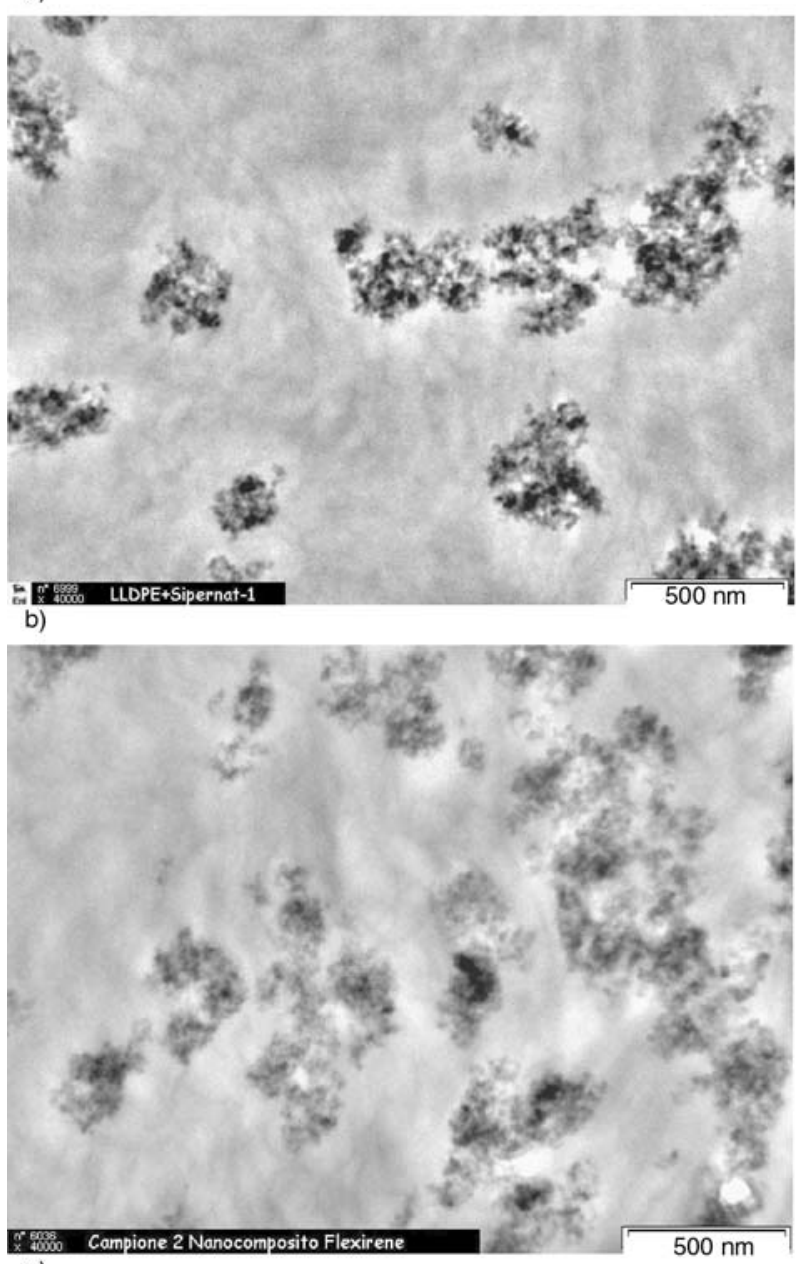

c)

Figure 1. ESEM and TEM images of the fracture surfaces of LLDPE - 2 vol\% composites: (a) LLDPEGlass-2, (b) LLDPE-S160-2, (c) LLDPE-A380-2

Isayev for polydimethylsiloxane [47] and by Uotila et al. for polypropylene [48]. The mean diameter of S160 aggregates is comparable to that of A380 aggregates, consisting of isodimensional domains of about $200 \mathrm{~nm}$ homogeneously dispersed in the matrix. Therefore, despite the differences in the initial dimensions of the particles, the final micro- 
structure of precipitated silica and fumed silica composites is very similar.

\subsection{Rheological measurements}

The effect of the filler content on the isothermal $\left(190^{\circ} \mathrm{C}\right)$ frequency dependence of the dynamic shear storage modulus $\left(G^{\prime}\right)$ of the prepared composites is reported in Figure 2. In the case of LLDPE-Glass-x samples, the typical rheological behaviour of microparticles filled polymers can be observed [50-53], with only a marginal improvement of $G^{\prime}$ in the entire frequency range. For precipitated silica composites the rheological behaviour is completely different. A strong $G^{\prime}$ enhancement can be easily detected even at relatively low silica content $(\Phi>2 \mathrm{vol} \%)$, especially in the low frequency region. These observations are in agreement with the existing scientific literature on the rheological properties of nanoparticles filled sys-
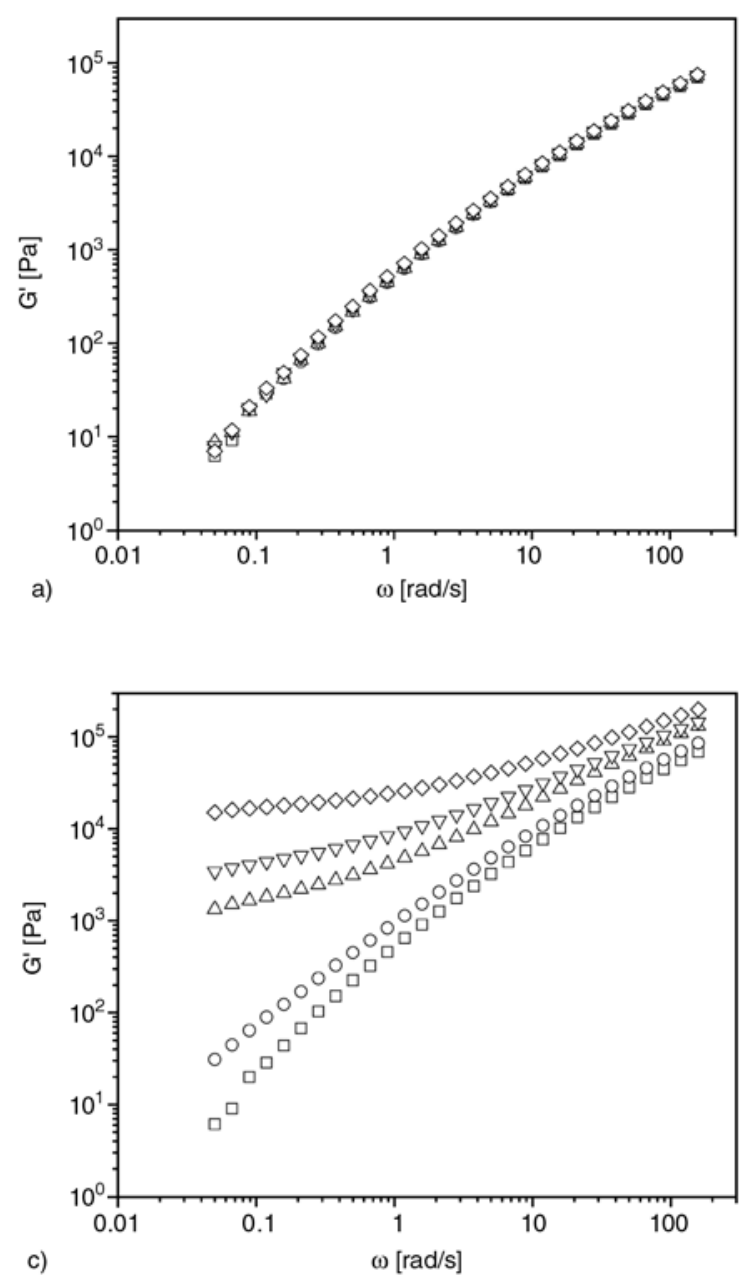

tems $[1,28,29,32,33,38,54]$. It is important to underline that $G^{\prime}$ of nanocomposites tends to become frequency independent in the low frequency region, which is the characteristic behaviour of an elastic solid (solid-like behaviour). According to Cassagnau [38], a similar trend observed in the low frequency region of polymerclay nanocomposites can be attributed to strong interactions between the clay layers and the polymeric matrix, while the solid-like behaviour in fumed silica nanocomposites could be related to particle-particle interactions and to the consequent formation of a netlike structure. These interactions may arise from hydrogen bonds between the silanol groups on the surface of primary nanoparticles. As can be visualized in TEM images reported in Figure 1 , fumed silica primary nanoparticles are fused together in aggregates, forming physical agglomerates with a diameter of $200-300 \mathrm{~nm}$. In these conditions it is possible to hypothesize that the network
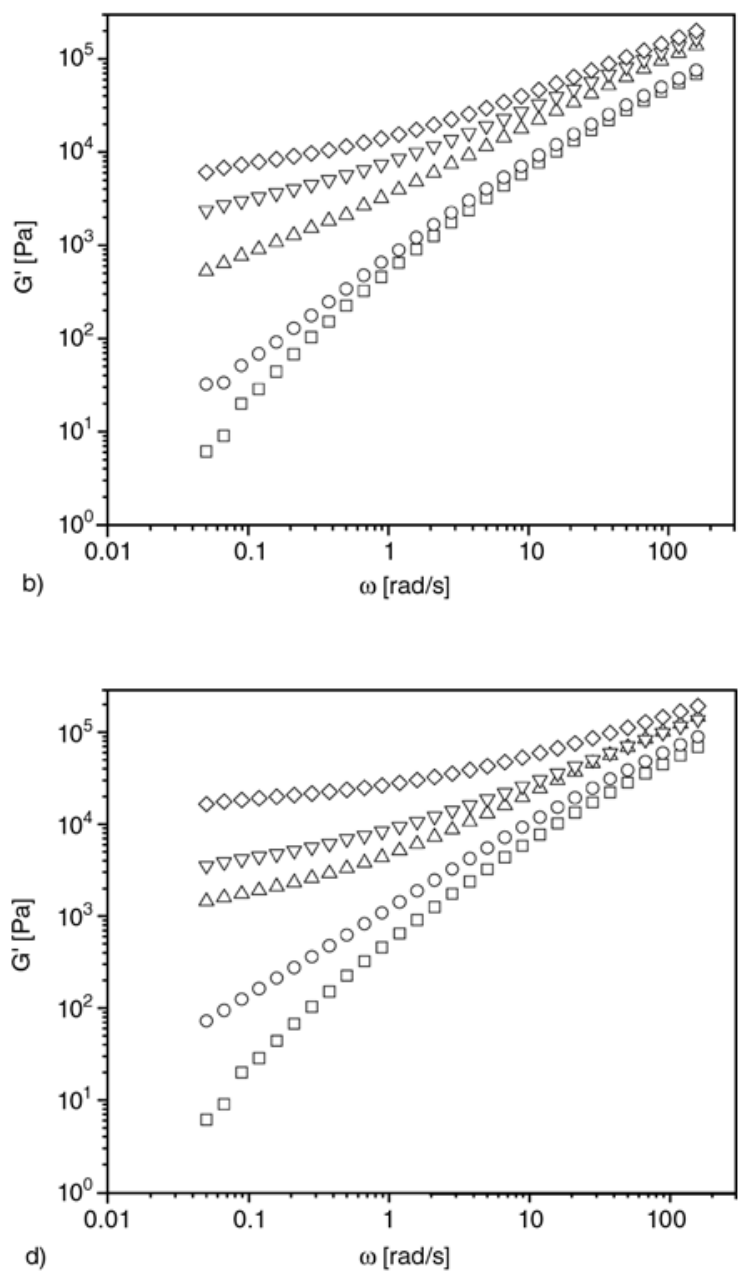

Figure 2. Storage modulus $\left(G^{\prime}\right)$ curves of LLDPE and relative composites $\left(T=190^{\circ} \mathrm{C}\right)$ : (a) LLDPE-Glass-x, (b) LLDPES160-x, (c) LLDPE-A200-x, (d) LLDPE-A380-x. (口) LLDPE, (O) $x=1 \mathrm{vol} \%,(\Delta) x=2 \mathrm{vol} \%,(\nabla) x=3 \mathrm{vol} \%$, $(\diamond) x=4$ vol\%. 
responsible of the solid like behaviour shown by the nanofilled samples is formed by particle-particle interactions between silanol groups present on the surface of the nanoparticles. In this way the physical interactions between the agglomerates create a space filling network, able to block the flow of LLDPE macromolecules. At high test frequencies these bonds can be destroyed by shear forces, and the $G^{\prime}$ values approach those of the unfilled matrix. The same considerations hold also for fumed silica nanocomposites, but in this case the increase of $G^{\prime}$ values with the filler content is even more evident, especially when nanoparticles with high SSA values are used.

Loss tangent $(\tan \delta)$ curves for pure LLDPE and relative micro- and nanocomposites are reported in Figure 3. Even in this case, the huge difference between the effects of glass microbeads and other fillers on the rheological behaviour of LLDPE is confirmed. If glass filled microcomposites are considered, the variation of the loss tangent is very lim-
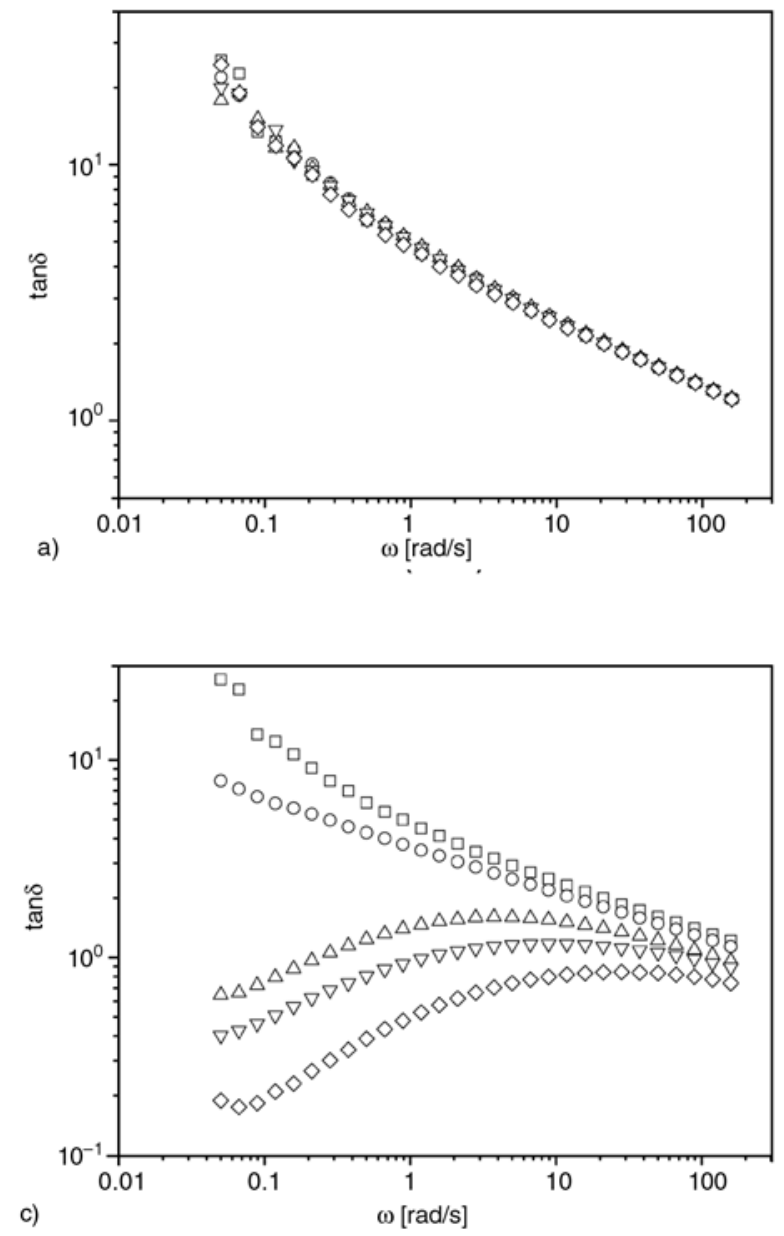

ited even at high filler contents, while both precipitated and fumed silica induce a remarkable decrease of $\tan \delta$, accompanied by a shift of the peak of $\tan \delta$ towards higher frequencies. The presence of a $\tan \delta$ peak can be probably associated to the beginning of the breakdown of the silica network. Therefore, the little shift of the $\tan \delta$ peak towards higher frequencies can be attributed to stronger interparticle interactions, favoured by the presence of a high number of silanol groups on the surface of the particles. Even in this case, the observed trend is more pronounced when fumed silica nanocomposites are considered, probably for the formation of an extended space filling silica network, due to the higher availability of silanol groups on the surface of primary nanoparticles. The hypothesis of the silica breakdown at $\tan \delta$ peak is supported by various literature references. For example, $\mathrm{Wu}$ and Zheng [55] studied the dynamic rheological behaviour of HDPE/CB (carbon black) nanocomposites. They found that increasing the $\mathrm{CB}$
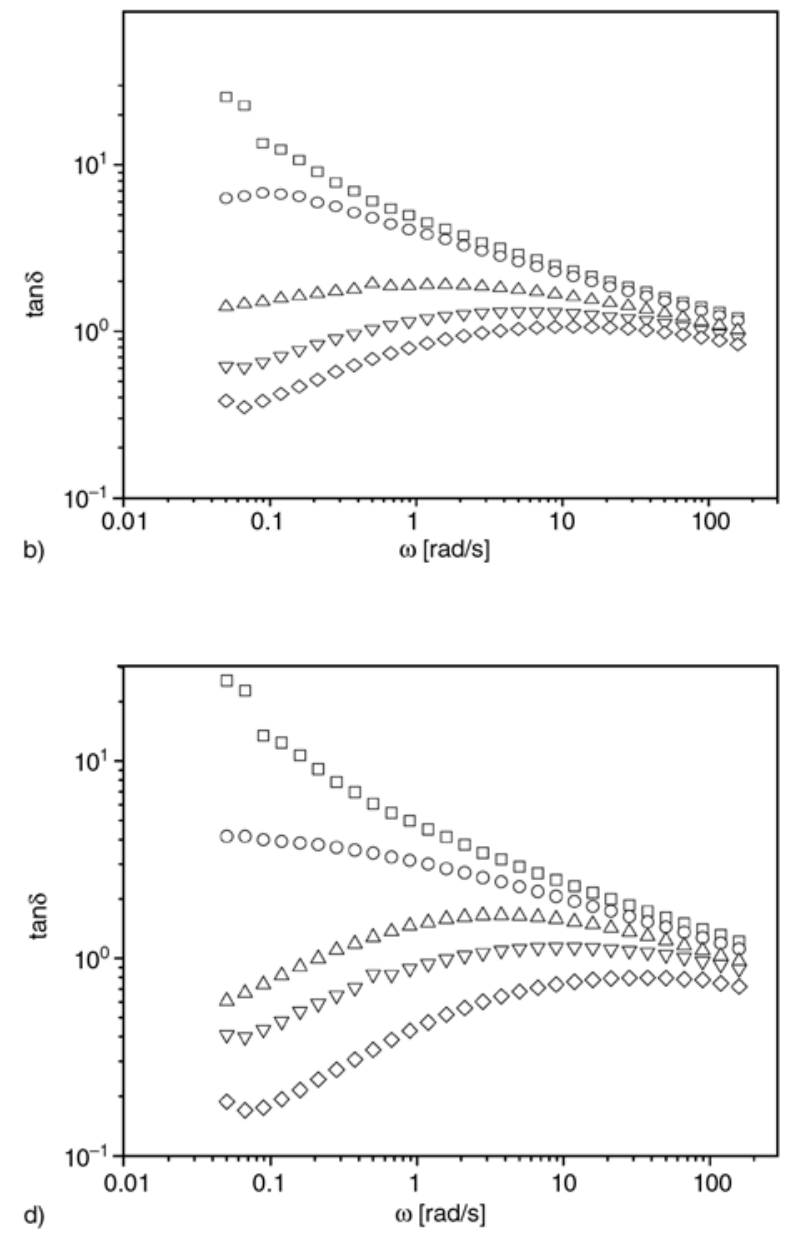

Figure 3. Loss tangent $(\tan \delta)$ curves of LLDPE and relative composites $\left(T=190^{\circ} \mathrm{C}\right)$ : (a) LLDPE-Glass-x, (b) LLDPES160-x, (c) LLDPE-A200-x, (d) LLDPE-A380-x. (口) LLDPE, (O) $x=1 \mathrm{vol} \%,(\Delta) x=2 \mathrm{vol} \%,(\nabla) x=3 \mathrm{vol} \%$, $(\diamond) x=4 \operatorname{vol} \%$. 
concentration, the plot of tan $\delta$ versus $\omega$ changed from linearity to an arc-shaped trend, with smaller $\tan \delta$ values in the low frequency region. Considering that the peak of tan $\delta$ appeared for $\mathrm{CB}$ concentrations higher than $9 \mathrm{vol} \%$, they defined this filler loading as a percolation threshold. Even in that case the magnitude of the peak decreased with an increase in the filler concentration, whereas tan $\delta$ values corresponding to the peak increased with the filler concentration. Romani et al. [56] attributed the existence of a $\tan \delta$ peak to a critical relaxation behavior involved in a high-order structure within the polymer matrix, related to the existence of interparticle networks. Therefore, it is likely that similar considerations could be extended to LLDPE filled with aggregated physically interacting nanoparticles.

Figure 4 reports the frequency dependence of the shear viscosity for pure LLDPE and relative microand nanocomposites. Even in this case, only marginal viscosity increments can be detected for glass beads filled microcomposites, with the presence of a Newtonian plateau at low frequencies. For precip-
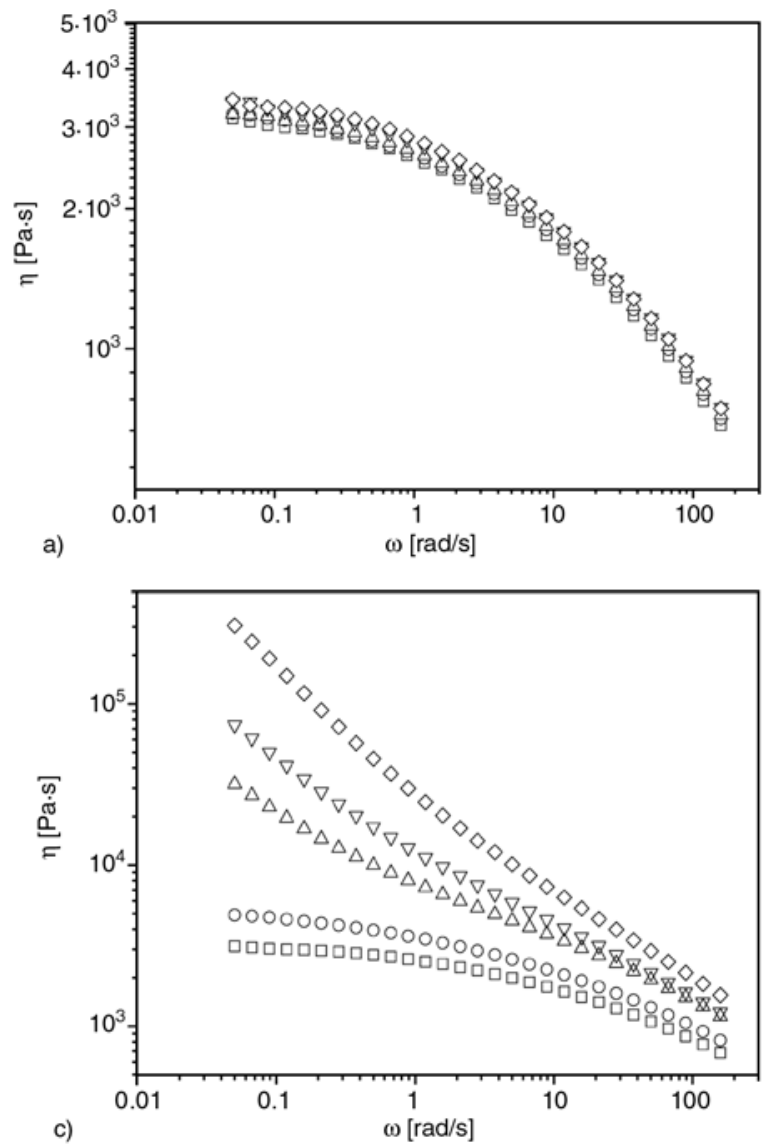

itated silica microcomposites and fumed silica nanocomposites viscosity enhancement is very pronounced, especially at low frequencies and for high silica loadings. The pseudoplastic plateau disappears for filler contents higher than $2 \mathrm{vol} \%$, probably for the formation of a network of hydrogen bonded silica aggregates. The effect of fumed silica specific surface area can be evidenced only at low frequencies, with an increase of the shear viscosity as SSA increases. The increase of surface area may result in a higher number of silanol groups on the surface of the aggregates, leading to a higher number of hydrogen bonds and, consequently, to stronger particle-particle interactions. Therefore, the noticeable increase of shear viscosity values could be attributed to the interparticle interactions arising from hydrogen bonds between silanol groups present on the surface of the particles. This hypothesis is widely supported in the literature not only for suspensions, but also for filled polymer matrices in the molten state. As mentioned before, Cassagnau [38] concluded that the viscosity enhancement in polymer-clay nanocomposites was
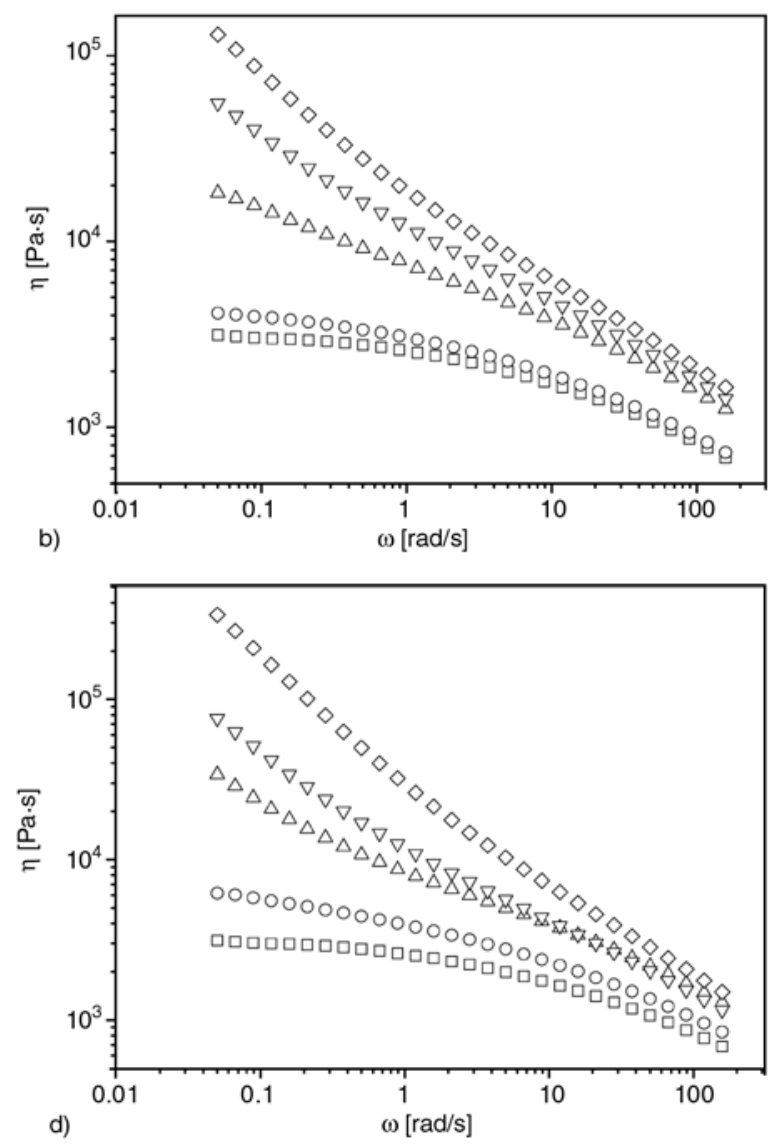

Figure 4. Viscosity $(\eta)$ curves of LLDPE and relative composites $\left(T=190^{\circ} \mathrm{C}\right)$ : (a) LLDPE-Glass-x, (b) LLDPE-S160-x, (c) LLDPE-A200-x, (d) LLDPE-A380-x. () LLDPE, (O) $x=1 \operatorname{vol} \%,(\Delta) x=2 \operatorname{vol} \%,(\nabla) x=3 \operatorname{vol} \%$, $(\diamond) x=4 \mathrm{vol} \%$. 
due to strong interactions between the clay layers and the polymeric matrix, while the solid-like behaviour in fumed silica nanocomposites was related to particle-particle interactions and to the subsequent formation of a netlike structure. This hypothesis is supported also by Bartholome [40], that considered filler networking due to the formation of hydrogen bonds as a first order parameter for silica nanocomposites based on common thermoplastics. Furthermore, considering that polyethylene has no polar groups in the main backbone, the possibility of having strong polymer-filler interactions and the physical absorption of polymer chains on the filler surface at the molten state appears relatively weak. Regarding the correlation between the viscosity drop and the destruction of the interparticle hydrogen bonds at high frequencies, it has to be considered that the higher the frequency the lower is the stress relaxation during each loading cycle
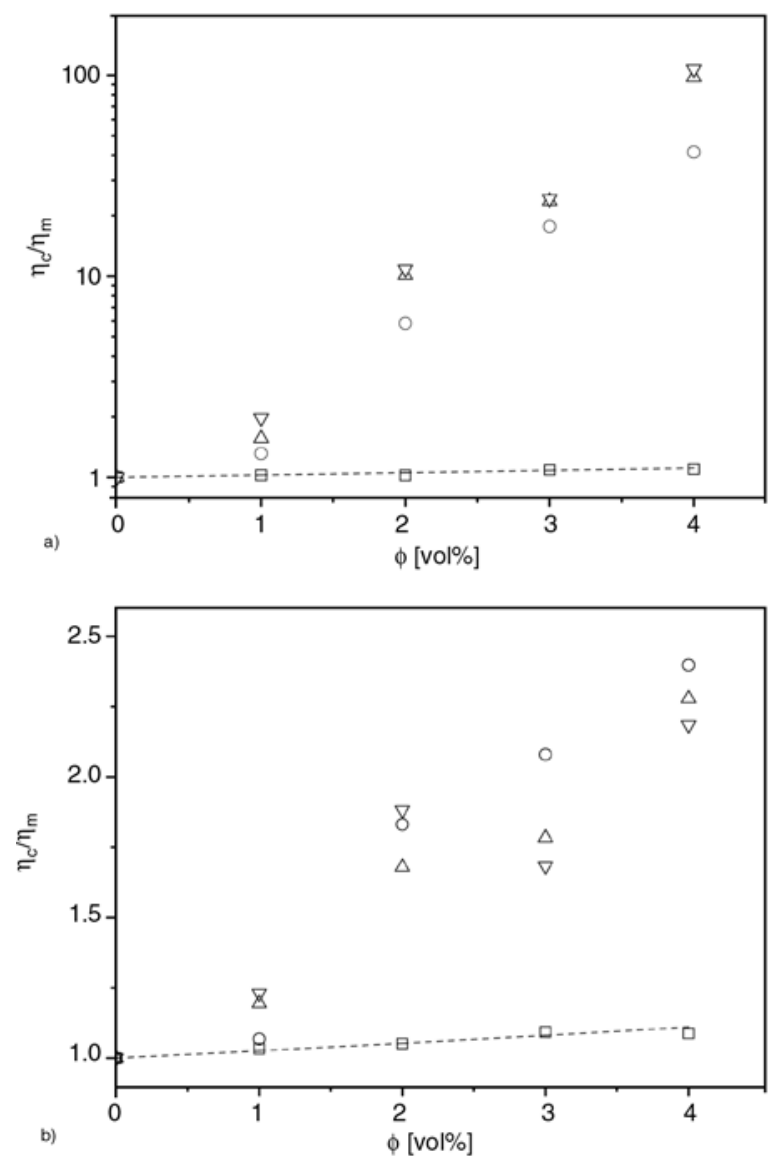

Figure 5. Relative viscosity values of LLDPE and relative composites $\left(T=190^{\circ} \mathrm{C}\right)$ at (a) $\omega=0.05 \mathrm{rad} / \mathrm{s}$ and (b) $\omega=158 \mathrm{rad} / \mathrm{s}$. (口) LLDPE-Glass-x, (o) LLDPE-S160-x, ( $\Delta$ ) LLDPE-A200-x, $(\nabla)$ LLDPE-A380-x. The dashed line represents the theoretical prediction of the relative viscosity according to the Batchelor model. and the higher is the stress acting transferred from the LLDPE matrix to the filler. This means that at high frequencies the energy involved to deform LLDPE macromolecules is much higher and perhaps superior to the energy required to break interparticle interactions. This hypothesis could also explain why the rheological behaviour of filled samples at high shear rates is similar to that of the unfilled matrix.

In order to better analyze the effect of the filler content on the rheological behaviour of the investigated micro and nanocomposites, relative viscosity at low $(0.05 \mathrm{rad} / \mathrm{s})$ and high $(158 \mathrm{rad} / \mathrm{s})$ frequencies has been reported in Figure 5 as a function of the volume content of the various fillers. It is clearly evident that the enhancement of the viscosity is much more pronounced at low frequencies, when the interparticle forces due to hydrogen bonding are more effective. While at $0.05 \mathrm{rad} / \mathrm{s}$ the viscosity of the LLDPE-A380-4 sample is about 100 times higher than that of the pure LLDPE, at $158 \mathrm{rad} / \mathrm{s}$ the viscosity of the same sample is only 2.4 times higher than that of the unfilled matrix. This confirms that in the high frequency regime the shear forces may lead to a breakage of the silica network, with a considerable reduction of viscosity values.

\subsection{Modelling}

Batchelor proposed a model to estimate the relative viscosity of polymer composites containing colloidal hard spheres in the limit of low shear rate, represented by the following Equation (1) [43]:

$\frac{\eta_{c}}{\eta_{m}}=1+2.5 \Phi+6.2 \Phi^{2}$

where $\eta_{c}$ and $\eta_{m}$ are the viscosity of the composite and of the matrix, respectively. It can be easily noted that the proposed model is an extension of the Einstein equation [57], originally proposed to predict the effect of a rigid filler on the viscosity of a Newtonian liquid in the case of diluite suspension. Considering that the filler content in the prepared composites is relatively small ( $\leq 4 \mathrm{vol} \%)$, it is possible to use the above mentioned expression in order to fit shear viscosity data, as reported in Figure 5. It is immediately evident that the Batchelor model is able to fit the viscosity trend of glass filled LLDPE composites, both in the low and in the high frequency regions, while in the case of precipitated 
silica and fumed silica composites the increase in relative viscosity is largely underestimated. As it could be expected, this model is unsuitable to catch the dependence of the rheological behaviour of polymeric nanocomposites from the filler content. In the last decades quite a variety of empirical nonNewtonian viscosity models, constituted by $2,3,4$ or 5 elements, have been proposed to analyze the frequency dependence of the shear viscosity of polymers [51]. For the materials investigated in this work the difficulty to find a suitable expression arises from the markedly different viscosity trends between unfilled LLDPE and fumed silica nanocomposites, due to the disappearance of the pseudoplastic plateau in the low frequency regime.

From a historical point of view, the first attempt to solve the problems related to the appearance of an yield stress at vanishing shear rates was made by Bingham [58] in 1922, that proposed a model with two distinct constitutive equations to describe the rheological behaviour of the material at rest and during the flow. As reported by Malkin [53], the abovementioned expression should not be intended as rheological equation of state, because it only contains an empirical description of experimental data obtained in unidimensional shear deformations. Also Barnes [50] specified that this law is basically empirical in nature and arising from curve-fitting exercises. Furthermore, the same authors underlined that the derived equation could be applied over limited parts of the flow curve, and care should be taken in the use of these models when employed outside a certain shear rate range. However, Bingham model did not prove to be suitable for numerical analysis because in some complex applications parts of material flow while the rest behaves as a solid, with considerable difficulties in applying two different constitutive equations across them. To overcome these issues, Papanastasiou [59] proposed a modification of the Bingham model, but his expression resulted to be not sufficiently effective in predicting the rheological behavior of shear thinning fluids with a yield stress, typical of complex fluids. More recently, Mitsoulis et al. [45] modified the Herschel-Bulkley model [60] to predict shear thinning behavior of complex fluids, with an expression reported in Equation (2):

$$
\eta=k \omega^{n-1}+\tau_{0} \omega^{-1}\left[1-e^{-m \omega}\right]
$$

It is evident that when the parameter $n$ is less than one, which is the typical case for shear-thinning fluids, the apparent viscosity tends to infinity when the shear rate tends to zero. Moreover, the dimension of parameter $k$ depends on parameter $n$. This may cause a problem when constructing a parameter with the unit of time based on the parameters $k$ and $n$ [51]. In 1980, De Kee and Turcotte proposed a three-parameter model [44] described by the following Equation (3):

$\eta=\tau_{0} \omega^{-1}+\eta_{1} e^{-t_{1} \omega}$

The first term on the right side of the equation includes a constant yield stress $\tau_{0}$. This parameter is closely related to the breakage of the solid network formed by silica aggregates. The limiting viscosity $\eta_{1}$ represents the zero-shear viscosity value when the solid network is absent, while $t_{1}$ is a characteristic time, related to the velocity of the viscosity drop at high frequencies. Even in this case characteristic time and limiting viscosity were presented by the authors as empirical parameters, with no evident physical meaning or correlation with material parameters. Carreau underlined that $\eta_{1}$ and $t_{1}$ had to be intended as analytical model parameters and not as real material properties [51]. In the scientific literature it is often reported that this model fits very well viscosity data in the low frequency region, while deviations may be expected when the high frequency region is considered [52].

As reported in Equation (4), a modification of the original De Kee-Turcotte model has been proposed by Zhu et al. [46], in order to predict a finite value of the apparent viscosity when the shear rate approaches zero:

$\eta=\tau_{0} \omega^{-1}\left[1-e^{-m \omega}\right]+\eta_{1} e^{-t_{1} \omega}$

In this expression, the dimensions of the parameters involved are independent of each other, and the apparent viscosity is bounded at vanishing shear rate. Even in this case the authors proposed this model without attributing any physical meaning to the various parameters of the expression, and the comparison with the previous models was carried out only on the basis of their fitting capabilities. Considering the need of proper empirical models that could satisfactorily describe the dynamic rheological behaviour of polymer melts in a certain shear rate region, we are proposing a modification of the original De Kee-Turcotte expression in order 
to obtain a satisfactory fitting of the rheological data in the high frequency region. In particular, the following empirical Equation (5) is proposed:

$$
\eta=\tau_{0} \omega^{-1}+\eta_{1} e^{-t_{1} \omega^{\alpha}}
$$

It can be noted that a new parameter $\alpha$ is introduced the second term of the De Kee-Turcotte equation. This should improve the ability of the model to follow the non-linear viscosity drop at high frequencies as observed for the nanocomposites at high filler contents.

The fitting capabilities of the above mentioned models (Equations 2 to 5) are compared in Figure 6 in the case of pure LLDPE and A380 filled samples, while Table 2 summarizes the coefficient of linear regression $\left(R^{2}\right)$ for the various fitting curves. It is evident that the expression proposed by Mitsoulis-Abdali (Equation 2) provides a good fitting for the pure LLDPE $\left(R^{2}=0.9961\right)$, while viscosity values of LLDPE-A380-2 samples in the high frequency region are underestimated. As displayed in Figure $6 \mathrm{c}$, this expression is not suitable to model the experimental data of nanocomposites at relatively high filler contents. As previously reported by other authors [52], even our data confirm that the original De Kee-Turcotte model (Equation 3) is not able to catch the rheological trends in the high frequency region, especially when a high amount of silica is added. The generalization proposed by Zhu (Equation 4), seems to improve the prediction capability of this model, even if some deviations are still evident in the high frequency region. It is evident that our model (Equation 5) is able to satisfactorily fit the viscosity data over the entire frequency range both for pure LLDPE and relative fumed silica nanocomposites $\left(R^{2}\right.$ values higher than 0.999). The model proposed in this paper provides a satisfactory fitting of the viscosity-frequency curves for all the investigated materials (see Figure 7). In the case of the pure LLDPE sample, the experimental viscosity trend in the high frequencies region is not linear and can be modelled by a simple $\omega^{\alpha}$ dependency, with the introduction of the $\alpha$ parameter that helps to fit more accurately the viscosity drop. For relatively high filler loadings
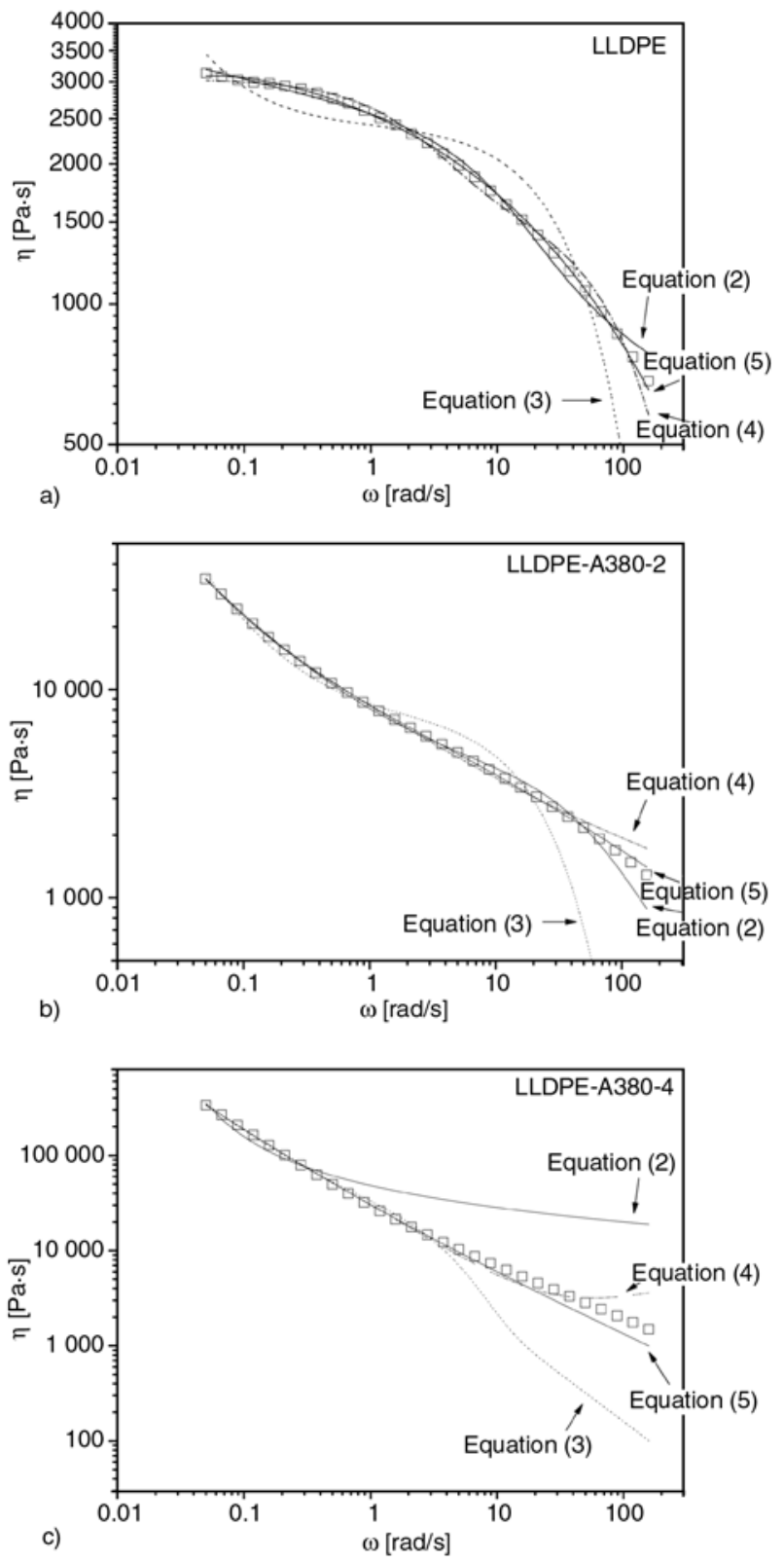

Figure 6. Experimental viscosity ( $\eta$ ) curves of (a) pure LLDPE, (b) LLDPE-A380-2 and (c) LLDPEA380-4 nanocomposites $\left(T=190^{\circ} \mathrm{C}\right)$, with the fitting lines according to various models. Mitsoulis-Abdali model (Equation (2)), De KeeTurcotte model (Equation (3)), Zhu model (Equation (4)), and the new model proposed in this work (Equation (5)).

Table 2. $R^{2}$ values from the fitting of shear viscosity data of LLDPE, LLDPE-A380-2 and LLDPE-A380-4 samples with different models

\begin{tabular}{|l|c|c|c|c|}
\hline & $\begin{array}{c}\text { Mitsoulis-Abdali } \\
\text { (Equation (2)) }\end{array}$ & $\begin{array}{c}\text { De Kee-Turcotte } \\
\text { (Equation (3)) }\end{array}$ & $\begin{array}{c}\text { Zhur model } \\
\text { (Equation (5)) }\end{array}$ \\
\hline LLDPE & 0.9962 & 0.8953 & 0.9952 & 0.9994 \\
\hline LLDPE-A380-2 & 0.9994 & 0.9839 & 0.9993 & 0.9999 \\
\hline LLDPE-A380-4 & 0.9441 & 0.9983 & 0.9997 & 0.9998 \\
\hline
\end{tabular}



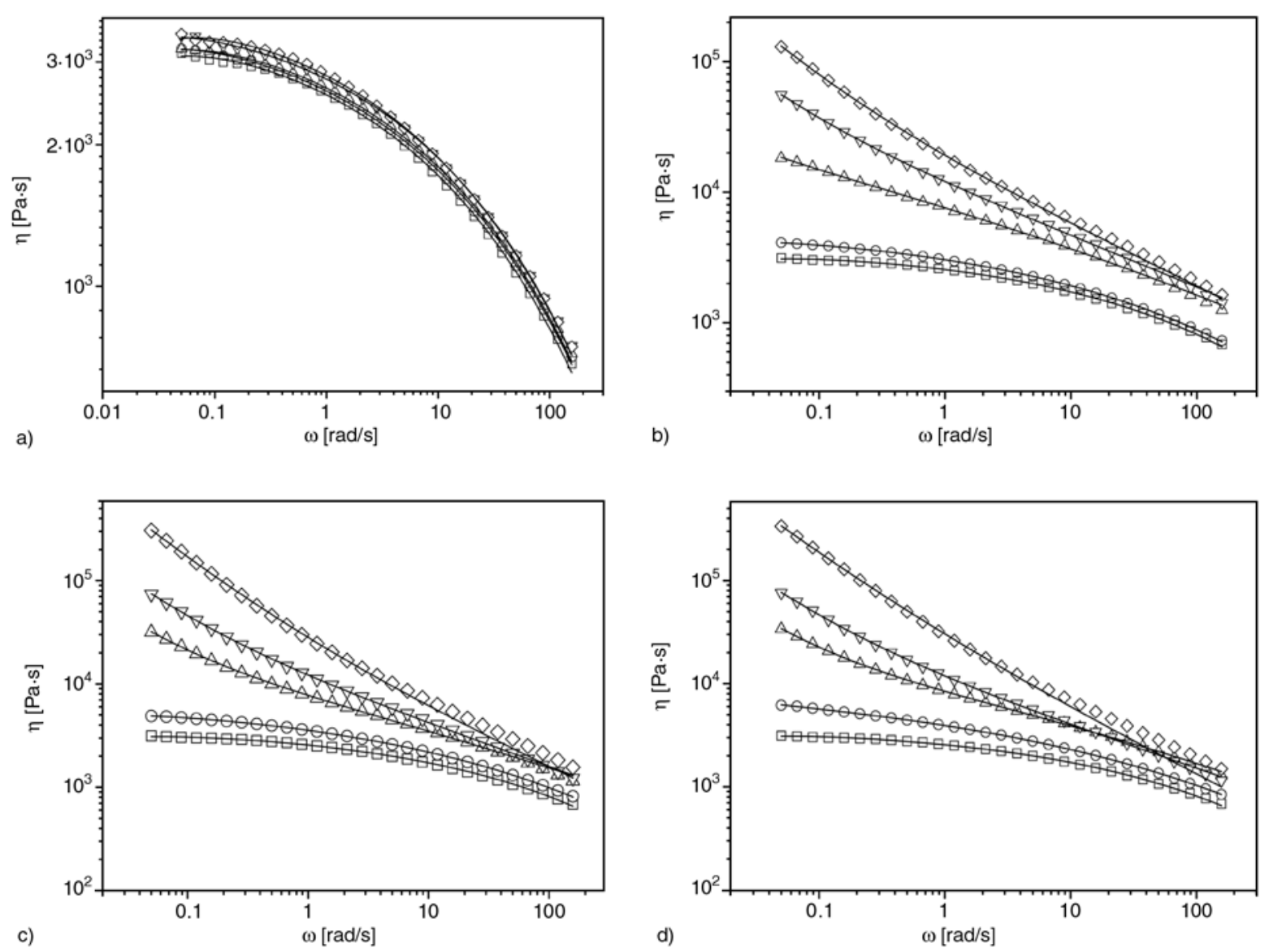

Figure 7. Experimental viscosity $(\eta)$ curves of LLDPE and relative composites $\left(T=190^{\circ} \mathrm{C}\right)$. (a) LLDPE-Glass-x,

(b) LLDPE-S160-x, (c) LLDPE-A200-x, (d) LLDPE-A380-x. () LLDPE, (o) $x=1$ vol\%, ( $\Delta$ ) $x=2$ vol\%, $(\nabla) x=3 \mathrm{vol} \%,(\diamond) x=4 \mathrm{vol} \%$. The continuous lines represent the fitted data according to the Modified De Kee-Turcotte model.

$(\Phi>2$ vol $\%)$ the value of $t_{1}$ tends to infinity and the second term of equation is practically zero. This means that the viscosity values are basically inversely proportional to the frequency. Considering the relatively high shear stress values for these composites, in the high frequency region viscosity values approach to zero with a trend similar to that of a line with a negative slope. This is the reason why in the considered frequency range the proposed model can be utilized both for the unfilled sample and for the nanocomposites.

Some additional considerations can be formulated by examining Figure 8 , in which the influence of the filler content and type on the fitting parameters of Equation (5) is represented. A non-zero yield stress parameter $\left(\tau_{0}\right)$ can be related to the presence of a filler network in the material [51, 52]. As documented in Figure 8a, it is evident that yield stress $\left(\tau_{0}\right)$ is practically zero for pure LLDPE and glass filled composites. For precipitated silica filled composites yield stress starts to increase after a filler content of $2 \mathrm{vol} \%$, while for fumed silica nanocomposites the enhancement of parameter $\tau_{0}$ is evident even at a filler loading of $1 \mathrm{vol} \%$. Therefore, the silica concentration after which yield stress increases can be interpreted as a percolation threshold, a critical filler loading after which the interparticle interactions may lead to the formation of a solid space filling network, and the viscosity greatly increases. In other words, the existence of a critical silica concentration above which the distance between the agglomerates is sufficiently low to allow the formation of a space filling network can be hypothesized. The appearance of a yield stress in shear viscosity curves for silica contents higher than $1 \mathrm{vol} \%$ is a direct proof of the network formation.

After the percolation threshold, traditional pseudoplastic behaviour of LLDPE, with a Newtonian plateau in the low frequency regime, disappears. Similar considerations hold for the limiting viscosity parameter $\eta_{1}$. For pure LLDPE and glass filled 

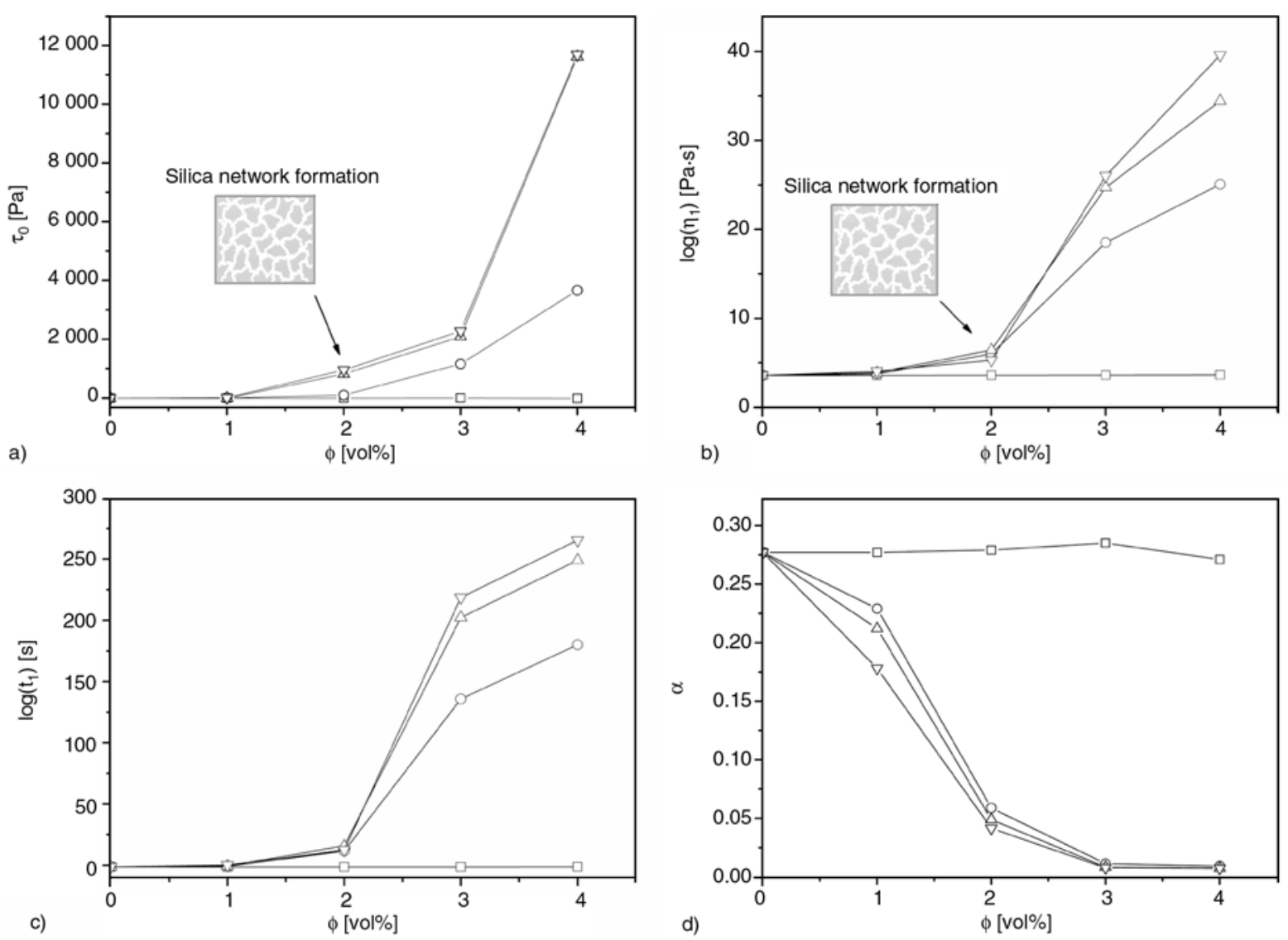

Figure 8. Evaluation of the Modified De Kee-Turcotte parameters derived from the fitting of the viscosity curves of LLDPE and relative composites: (a) $\tau_{0}$, (b) $\eta_{1}$, (c) $t_{1}$, (d) $\alpha$. (口) LLDPE-Glass-x, (o) LLDPE-S160-x,

$(\Delta)$ LLDPE-A200-x, ( $\nabla$ ) LLDPE-A380-x.

composites this parameter assumes a value of about 3000-4000 Pa.s, and it can be considered as the zero shear viscosity. For the other composites $\eta_{1}$ begins to increase for filler contents as low as $2 \mathrm{vol} \%$. It is important to underline that at elevated silica volume fractions $(3-4 \mathrm{vol} \%) \eta_{1}$ value is around $10^{30} \mathrm{~Pa} \cdot \mathrm{s}$, i.e. a typical viscosity value of a solid material. Even $t_{1}$ confirms this picture. In fact, this parameter rules the viscosity drop at high frequencies. For glass filled composites $t_{1}$ is practically the same of unfilled LLDPE, while for precipitated and fumed silica composites the characteristic time begins to increase for a silica loading higher than $2 \mathrm{vol} \%$. Considering that the evaluation of the fitting parameters was carried out from an analytical point of view, the representation of the $t_{1}$ parameter with values of 10 up to the power 200 for the nanofilled samples underlines the fact that at high silica contents $t_{1}$ tends to infinity and the second term of the equation approaches to zero, leading to a $\omega^{-1}$ dependency with an high yield stress value. For the same reason $\alpha$ parameter is practically insensitive to the filler content for glass filled composites, while for precipitated and fumed silica filled samples $\alpha$ considerably drops with the filler content.

\section{Conclusions}

The effect of the filler morphology (mean particle size and surface area) on the dynamic rheological properties of LLDPE/silica micro- and nanocomposites was investigated on melt compounded samples.

TEM images revealed that fumed silica and precipitated silica composites are characterized by similar microstructures, with the presence of spherical silica aggregates homogeneously dispersed in the matrix, having a mean diameter lower than $400 \mathrm{~nm}$. On the other hand, in traditional glass microcomposites spherical smooth microparticles, with mean size of about 15-20 $\mu \mathrm{m}$, can be easily detected. The dispersion of silica aggregates at the nanoscale was strictly correlated to the rheological behaviour of the composites. While in the case of glass microbeads filled samples only marginal effects on 
dynamic rheological properties could be detected, a very strong enhancement of the storage modulus $\left(G^{\prime}\right)$ and of the viscosity $(\eta)$ with the filler content, especially at low frequencies, was evidenced for fumed silica and precipitated silica composites, while loss tangent values were strongly reduced, with a shift of the tan $\delta$ peak towards higher frequencies. It was hypothesized that particle-particle interactions, arising from hydrogen bonds of silanolic groups present on the surface of primary nanoparticles, were effective in nanofilled samples, creating a space filling network able to block the viscous flow of LLDPE macromolecules.

Trying to find a suitable non-Newtonian model to fit shear viscosity data, a new empirical expression, based on a modification of the original threeparameter model proposed by De Kee and Turcotte, was successfully proposed. While in the case of glass filled samples fitting parameters were only marginally affected by the filler addition, when precipitated silica and fumed silica composites were considered a strong correlation with the filler loading was found.

\section{References}

[1] Sarvestani A. S.: Modeling the solid-like behavior of entangled polymer nanocomposites at low frequency regimes. European Polymer Journal, 44, 263-269 (2008).

DOI: $10.1016 /$ j.eurpolymj.2007.11.023

[2] Harzallah O., Dupuis D.: Rheological properties of suspensions of $\mathrm{TiO}_{2}$ particles in polymer solutions. 1 . Shear viscosity. Rheologica Acta, 42, 10-19 (2003). DOI: $10.1007 / \mathrm{s} 00397-002-0250-2$

[3] Le Meins J-F., Moldenaers P., Mewis J.: Suspensions in polymer melts. 1. Effect of particle size on the shear flow behavior. Industrial and Engineering Chemistry, 41, 6297-6304 (2002). DOI: $10.1021 / \mathrm{ie} 020117 \mathrm{r}$

[4] Osman M. A., Atallah A.: Interparticle and particlematrix interactions in polyethylene reinforcement of viscoelasticity. Polymer, 46, 9476-9488 (2005). DOI: $10.1016 /$ j.polymer.2005.07.030

[5] Osman M. A., Atallah A.: Effect of the particles size on the viscoelastic properties of filled polyethylene. Polymer, 47, 2357-2368 (2006). DOI: $10.1016 /$ j.polymer.2006.01.085

[6] Zhang Q., Archer L. A.: Optical polarimetry and mechanical rheometry of polyethyleneoxide-silica dispersions. Macromolecules, 37, 1928-1936 (2004). DOI: $10.1021 / \mathrm{ma} 035667 \mathrm{v}$
[7] Zhu T., Thompson T., Wang S-Q., von Meerwall E. D., Halasa A.: Investigating linear and nonlinear viscoelastic behavior using model silica-particle-filled polybutadiene. Macromolecules, 38, 8816-8824 (2005).

DOI: $\underline{10.1021 / \mathrm{ma} 050922 \mathrm{~s}}$

[8] Aranguren M. I., Mora E. M., DeGroot J. V., Macosko C. W.: Effect of reinforcing fillers on the rheology of polymer melts. Journal of Rheology, 36, 1165-1182 (1992).

DOI: $\underline{10.1122 / 1.550306}$

[9] Cassagnau P., Melis F.: Non-linear viscoelastic behaviour and modulus recovery in silica filled polymers. Polymer, 44, 6607-6615 (2003).

DOI: $10.1016 / \mathrm{S} 0032-3861(03) 00689-\mathrm{X}$

[10] Zhang Q., Archer L. A.: Poly(ethylene oxide)/silica nanocomposites: Structure and rheology. Langmuir, 18, 10435-10442 (2002). DOI: $10.1021 / \mathrm{la026338j}$

[11] Kohl D. J., Beaucage G.: Rational design of reinforced rubber. Current Opinion in Solid State and Materials Science, 6, 183-194 (2002). DOI: $\underline{10.1016 / \text { S1359-0286(02)00073-6 }}$

[12] Medalia A.: Morphology of aggregates: VI Effective volume of aggregates of carbon black from electron microscopy; Application to vehicle absorption and to die swell of filled rubber. Journal of Colloid and Interface Science, 32, 115-131 (1970). DOI: 10.1016/0021-9797(70)90108-6

[13] Osman M. A., Atallah A., Schweizer T., Ottinger H. C.: Particle-particle and particle-matrix interactions in calcite filled high-density polyethylene-steady shear. Journal of Rheology, 48, 1167-1184 (2004). DOI: $\underline{10.1122 / 1.1784782}$

[14] Piau J-M., Dorget M., Palierne J-F., Pouchelon A.: Shear elasticity and yield stress of silica-silicone physical gels: Fractal approach. Journal of Rheology, $\mathbf{4 3}$ 305-314 (1999). DOI: $10.1122 / 1.550989$

[15] Witten T. A., Rubinstein M., Colby R. H.: Reinforcement of rubber by fractal aggregates. Journal de Physique II, 3, 367-383 (1993). DOI: $10.1051 / \mathrm{jp} 2: 1993138$

[16] Wolthers W., van den Ende D., Breedveld V., Duits M. H. G., Potanin A., Wientjes R. H. W., Mellema J.: Linear viscoleastic behavior of aggregated colloidal dispersions. Physical Review E, 56, 5726-5733 (1997).

DOI: 10.1103/PhysRevE.56.5726

[17] Havet G., Isayev A.: A thermodynamic approach to the rheology of highly interactive filler-polymer mixtures: Part I Theory. Rheologica Acta, 40, 570-581 (2001). DOI: $10.1007 / \mathrm{s} 003970100176$ 
[18] Havet G., Isayev A.: A thermodynamic approach to the rheology of highly interactive filler-polymer mixtures. Part II. Comparison with polystyrene/nanosilica mixtures. Rheologica Acta, 42, 47-55 (2003). DOI: $10.1007 / \mathrm{s} 00397-002-0253-\mathrm{Z}$

[19] Montes H., Lequeux F., Berriot J.: Influence of the glass transition temperature gradient on the nonlinear viscoelastic behavior in reinforced elastomers. Macromolecules, 36, 8107-8118 (2003).

DOI: $10.1021 / \mathrm{ma} 0344590$

[20] Pryamitsyn V., Ganesan V.: Mechanisms of steadyshear rheology in polymer-nanoparticle composites. Journal of Rheology, 50, 655-683 (2006). DOI: $\underline{10.1122 / 1.2234483}$

[21] Pryamitsyn V., Ganesan V.: Origins of linear viscoelastic behavior of polymer-nanoparticle composites. Macromolecules, 39, 844-856 (2006).

DOI: $10.1021 / \mathrm{ma} 051841 \mathrm{z}$

[22] Simhambhatla M., Leonov A.: On the rheological modeling of filled polymers with particle-matrix interactions. Rheologica Acta 34, 329-338 (1995). DOI: $10.1007 / \mathrm{BF} 00367150$

[23] Dazhu C., Haiyang Y., Pingsheng H., Weian Z.: Rheological and extrusion behavior of intercalated highimpact polystyrene/organomontmorillonite nanocomposites. Composites Science and Technology, 65, 1593-1600 (2005).

DOI: $10.1016 /$ j.compscitech.2005.01.011

[24] Durmus A., Kasgoz A., Macosko C. W.: Linear low density polyethylene (LLDPE)/clay nanocomposites. Part I: Structural characterization and quantifying clay dispersion by melt rheology. Polymer, 48, 4492-4502 (2007).

DOI: $10.1016 /$ j.polymer.2007.05.074

[25] Gupta R. K., Pasanovic-Zujo V., Bhattacharya S. N.: Shear and extensional rheology of EVA/layered silicate-nanocomposites. Journal of Non-Newtonian Fluid Mechanics, 128, 116-125 (2005).

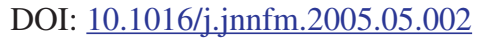

[26] Krishnamoorti R., Yurekli K.: Rheology of polymer layered silicate nanocomposites. Current Opinion in Colloid and Interface Science, 6, 464-470 (2001). DOI: 10.1016/S1359-0294(01)00121-2

[27] Ray S. S., Yamada K., Okamoto M., Ueda K.: New polylactide-layered silicate nanocomposites. 2. Concurrent improvements of material properties, biodegradability and melt rheology. Polymer, 44, 857866 (2003).

DOI: $10.1016 / \mathrm{S} 0032-3861(02) 00818-2$

[28] Sepehr M., Utracki L. A., Zheng X., Wilkie C. A.: Polystyrenes with macro-intercalated organoclay. Part II. Rheology and mechanical performance. Polymer, 46, 11569-11581 (2005). DOI: $10.1016 /$ j.polymer.2005.10.032
[29] Wu D., Wu L., Wu L., Zhang M.: Rheology and thermal stability of polylactide/clay nanocomposites. Polymer Degradation and Stability, 91, 3149-3155 (2006).

DOI: $10.1016 /$ j.polymdegradstab.2006.07.021

[30] Zhao J., Morgan A. B., Harris J. D.: Rheological characterization of polystyrene-clay nanocomposites to compare the degree of exfoliation and dispersion. Polymer, 46, 8641-8660 (2005).

DOI: 10.1016/j.polymer.2005.04.038

[31] Zhong Y., Zhu Z., Wang S. Q.: Synthesis and rheological properties of polystyrene/layered silicate nanocomposite. Polymer, 46, 3006-3013 (2005). DOI: 10.1016/j.polymer.2005.02.014

[32] Abdel-Goad M., Pötschke P.: Rheological characterization of melt processed polycarbonate multiwalled carbon nanotube composites. Journal of Non-Newtonian Fluid Mechanics, 128, 2-6 (2005).

DOI: $10.1016 /$ j.jnnfm.2005.01.008

[33] Ganß M., Satapathy B. K., Thunga M., Weidisch R., Pötschke P., Jehnichen D.: Structural interpretations of deformation and fracture behavior of polypropylene/multi-walled carbon nanotube composites. Acta Materialia, 56, 2247-2261 (2008).

DOI: $10.1016 /$ j.actamat.2008.01.010

[34] Hu G., Zhao C., Zhang S., Yang M., Wang Z.: Low percolation thresholds of electrical conductivity and rheology in poly(ethylene terephthalate) through the networks of multi-walled carbon nanotubes. Polymer, 47, 480-488 (2006).

DOI: $10.1016 /$ j.polymer.2005.11.028

[35] Prashantha K., Soulestin J., Lacrampe M. F., Claes M., Dupin G., Krawczak P.: Multi-walled carbon nanotube filled polypropylene nanocomposites based on masterbatch route: Improvement of dispersion and mechanical properties through PP-g-MA addition. Express Polymer Letters, 2, 735-745 (2008). DOI: $10.3144 /$ expresspolymlett.2008.87

[36] Prashantha K., Soulestin J., Lacrampe M. F., Krawczak P., Dupin G., Claes M.: Masterbatch-based multi-walled carbon nanotube filled polypropylene nanocomposites: Assessment of rheological and mechanical properties. Composites Science and Technology, 69, 1756-1763 (2009).

DOI: $10.1016 /$ j.compscitech.2008.10.005

[37] Song Y. S.: Rheological characterization of carbon nanotubes/poly(ethylene oxide) composites. Rheologica Acta, 46, 231-238 (2006). DOI: $10.1007 / \mathrm{s} 00397-006-0137-8$

[38] Cassagnau P.: Melt rheology of organoclay and fumed silica nanocomposites. Polymer, 49, 2183-2196 (2008). DOI: 10.1016/j.polymer.2007.12.035

[39] Kontou E., Niaounakis M.: Thermo-mechanical properties of LLDPE/SiO 2 nanocomposites. Polymer, 47, 1267-1280 (2006).

DOI: 10.1016/j.polymer.2005.12.039 
[40] Bartholome C., Beyou E., Bourgeat-Lami E., Cassagnau P., Chaumont P., David L., Zydowicz N.: Viscoelastic properties and morphological characterization of silica/polystyrene nanocomposites synthesized by nitroxide-mediated polymerization. Polymer, 46, 9965-9973 (2005).

DOI: 10.1016/j.polymer.2005.07.057

[41] Cassagnau P.: Payne effect and shear elasticity of silica-filled polymers in concentrated solutions and in molten state. Polymer, 44, 2455-2462 (2003).

DOI: 10.1016/S0032-3861(03)00094-6

[42] Inoubli R., Dagréou S., Lapp A., Billon L., Peyrelasse J.: Nanostructure and mechanical properties of polybutylacrylate filled with grafted silica particles. Langmuir, 22, 6683-6689 (2006).

DOI: $10.1021 / 1 \mathrm{a} 0607003$

[43] Batchelor G. K.: The effect of the Brownian motion on the bulk stress in a suspension of spherical particles. Journal of Fluid Mechanics, 83, 97-117 (1977). DOI: $10.1017 /$ S0022112077001062

[44] De Ké D., Turcotte G.: Viscosity of biomaterials. Chemical Engineering Communications, 6, 273-282 (1980).

DOI: $\underline{10.1080 / 00986448008912535}$

[45] Mitsoulis E., Abdali S. S., Markatos N. C.: Flow simulation of Herschel-Bulkley fluids through extrusion dies. The Canadian Journal of Chemical Engineering, 71, 147-160 (1993).

DOI: $\underline{10.1002 / \text { cjce. } 5450710120}$

[46] Zhu H., Kim Y. D., De Kee D.: Non-Newtonian fluids with a yield stress. Journal of Non-Newtonian Fluid Mechanics, 129, 177-181 (2005).

DOI: $10.1016 /$ j.jnnfm.2005.06.001

[47] Shim S. E., Isayev A. I.: Rheology and structure of precipitated silica and poly(dimethyl siloxane) system. Rheologica Acta, 43, 127-136 (2004).

DOI: $10.1007 / \mathrm{s} 00397-003-0327-6$

[48] Uotila R., Hippi U., Paavola S., Seppälä J.: Compatibilization of PP/elastomer/microsilica composites with functionalized polyolefins: Effect on microstructure and mechanical properties. Polymer, 46, 79237930 (2005).

DOI: $10.1016 /$ j.polymer.2005.06.099
[49] Brunauer S., Emmett P. H., Teller E.: Adsorption of gases in multimolecular layers. Journal of American Chemical Society, 60, 309-319 (1938).

[50] Barnes H. A., Hutton J. F., Walters K.: An introduction to rheology. Elsevier, Amsterdam (1989).

[51] Carreau P. J., De Kee D. C. R., Chhabra R. P.: Rheology of polymeric systems. Hanser, Munich (1997).

[52] Gupta R. K.: Polymer and composite rheology. Marcel Dekker, New York (2000).

[53] Malkin A. Y.: Rheology fundamentals. ChemTech Publishing, Toronto (Canada) (1994).

[54] Renger C., Kuschel P., Kristoffersson A., Clauss B., Oppermann W., Sigmund W.: Rheology studies on highly filled nano-zirconia suspensions. Journal of the European Ceramic Society, 27, 2361-2367 (2007). DOI: 10.1016/j.jeurceramsoc.2006.08.022

[55] Wu G., Zheng Q.: Estimation of the agglomeration structure for conductive particles and fiber-filled highdensity polyethylene through dynamic rheological measurements. Journal of Polymer Science Part B: Polymer Physics, 42, 1199-1205 (2004).

DOI: $10.1002 /$ polb. 10773

[56] Romani F., Corrieri R., Braga V., Ciardelli F.: Monitoring the chemical crosslinking of propylene polymers through rheology. Polymer, 43, 1115-1131 (2002).

DOI: $\underline{10.1016 / \mathrm{S} 0032-3861(01) 00679-6}$

[57] Einstein A.: Investigations on the theory of the brownian movement. Dover Publications, New York (1956).

[58] Bingham E. C.: Fluidity and plasticity. McGraw-Hill, New York (1922).

[59] Papanastasiou T. C.: Flows of materials with yield. Journal of Rheology, 31, 385-404 (1987).

[60] Herschel W. H., Bulkley R.: Konsistenzmessungen von Gummi-Benzol-Losungen. Colloid and Polymer Science, 39, 291-300 (1926). DOI: $10.1007 / \mathrm{BF} 01432034$ 